\title{
KAJIAN PERANCANGAN HUNIAN SEHAT DAN TERJANGKAU BAGI PEKERJA MIGRAN
}

\section{TANAH ABANG}

\author{
Vinny Santoso ${ }^{1)}$, Diah Anggraini ${ }^{2)}$
}

1) Program Studi S1 Arsitektur, Fakultas Teknik, Universitas Tarumanagara, vinny_santoso@yahoo.com

2) Program Studi S1 Arsitektur, Fakultas Teknik, Universitas Tarumanagara, diah_ismono@yahoo.com

\begin{abstract}
ABSTRAK
Urbanisasi merupakan fenomena yang tidak dapat dihindarkan. Bappenas (2020) menyebutkan pertambahan penduduk DKI Jakarta naik $0,7 \%$ yaitu bertambah 72 ribu jiwa dari tahun sebelumnya, sehingga menjadi 10,57 juta jiwa. Namun rendahnya bekal pendidikan dan ketrampilan yang mereka miliki, menjadi salah satu faktor meningkatnya jumlah pekerja migran pada sektor informal. Sementara adanya peluang bagi para pekerja informal khususnya para migran di DKI Jakarta tidak didukung dengan ketersediaan tempat tinggal disekitar kawasan yang layak dan terjangkau, sehingga menjadi masalah tumbuhnya permukiman kumuh/ liar yang tidak mendukung kehidupan yang sehat di sekitar kawasan tersebut. Studi ini bertujuan memberikan alternatif tempat berhuni bagi para migran yang bekerja pada sektor informal di bidang perdagangan dan jasa pada Kawasan Tanah Abang. Hasil akhir yang diharapkan adalah menghasilkan suatu konsep perancangan dan penerapannya pada desain hunian yang memenuhi kriteria sehat dan terjangkau bagi para migran khususnya yang bekerja di Kawasan Tanah Abang. Para migran di Kawasan ini sulit mendapatkan tempat tinggal di lokasi yang dekat dengan tempat kerja, agar dapat menghemat waktu dan biaya transportasi. Sistem sharing ruang pada kamar maupun fasilitas hunian, merupakan konsep hunian yang digunakan agar biaya tempat tinggal dapat terjangkau. Studi ini menggunakan metode dunia perilaku dengan pendekatan arsitektur keseharian, dilakukan pemetaan aktivitas dari para target penghuni, agar dapat menentukan kebutuhan ruang dan program dalam hunian yang sesuai. Konsep perancangan bangunan ini, hunian yang sehat dengan sirkulasi udara yang baik, mempunyai nilai keamanan, kenyamanan, dan keindahan meskipun tetap menerapkan prinsip keterjangkauan sehingga para migran yang bekerja di kota dapat hidup dengan layak.
\end{abstract}

Kata Kunci : Urbanisasi; Migran; Sehat; Terjangkau.

\begin{abstract}
Urbanization is a phenomenon that cannot be avoided. Bappenas (2020) states that the population growth of DKI Jakarta has increased by $0.7 \%$, which is an increase of 72 thousand people from the previous year, to become 10.57 million people. However, the lack of education and skills they have is one factor in the increasing number of migrant workers in the informal sector. Meanwhile, the opportunities for informal workers, especially migrants in DKI Jakarta, are not supported by the availability of adequate and affordable housing around the area, so that it becomes a problem for the growth of slum / illegal settlements that do not support a healthy life around the area. This study aims to provide an alternative place of residence for migrants who work in the informal sector in the trade and services sector in the Tanah Abang area. The final result expected is to produce a design concept and its application to shelter designs that meet the criteria of being healthy and affordable for migrants, especially those working in the Tanah Abang area. Migrants in this area find it difficult to find a place to live in a location close to the workplace, in order to save time and transportation costs. The system of sharing space in rooms and residential facilities is a residential concept used so that housing costs can be affordable. This study uses a behavioral world method with a daily architectural approach, mapping the activities of the target occupants, in order to determine the space requirements and the appropriate occupancy programs. The concept of designing this building, a healthy residence with good air circulation, has safety, comfort and beauty values even though it still applies the principle of affordability so that migrants who work in cities can live properly.
\end{abstract}

Keyword : Urbanization; Migrant; Health; Affordable. 


\section{PENDAHULUAN}

\section{Latar Belakang}

Dengan meningkatnya urbanisasi di kota-kota besar, banyak migran yang datang dan mencari pekerjaan di kota, seperti di DKI Jakarta. Kawasan Pasar Tanah Abang, Jakarta Barat menjadi salah satu kawasan yang banyak didatangi para pekerja migran karena banyak memiliki peluang pekerjaan sebagai pekerja informal, namun dengan upah yang didapatkan, mereka tidak memiliki cukup uang untuk tempat tinggal di sekita kawasan, sehingga harus tinggal di permukiman liar/kumuh. Kondisi tersebut saat ini semakin sulit karena terjadinya pandemik covid-19, yang menuntut perubahan dalam cara berhuni manusia, antara lain keharusan menjaga jarak, mengurangi interaksi dan kerumunan serta harus menjalani perilaku bersih dan dapat menjaga imunitas tubuh.

Maka dari itu, program fungsi yang akan diusulkan adalah membangun fasilitas tempat berhuni bagi para migran sektor informal Kawasan Pasar Tanah Abang dengan konsep Health and Affordable Housing.

Faktor Pendorong :

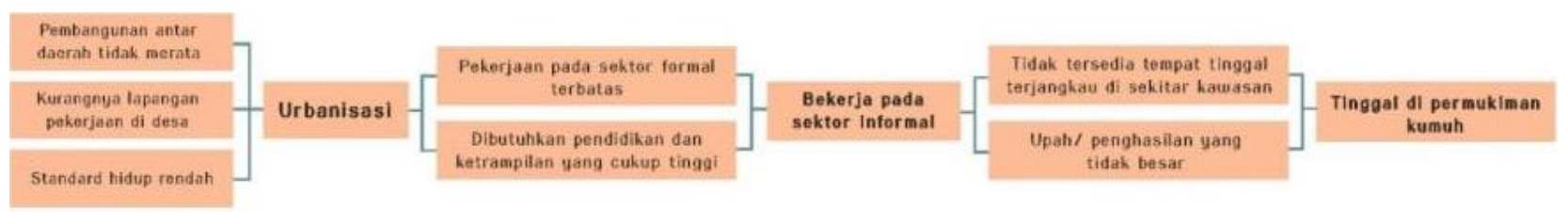

Gambar 1. Diagram Latar Belakang Proyek

Sumber: Penulis, 2020

\section{Rumusan Permasalahan}

a. Bagaimana konsep berhuni/ dwelling para pekerja migran di Kawasan Pasar Tanah Abang di masa mendatang, yang dapat meningkatkan kesejahteraan dan kesehatan mereka?

b. Bagaimana design, sistem, dan tipe shelter/ tempat berhuni yang sehat dan terjangkau bagi para migran di Kawasan Pasar Tanah Abang, dengan tetap mengantisipasi pengalaman saat ini, ketika terjadi pandemi yang berdampak luas terutama dalam cara dan kebiasaan berhuni?

\section{Maksud dan Tujuan}

Tujuan dari studi ini adalah untuk memberikan alternative tempat berhuni bagi para migran yang bekerja pada sektor informal di bidang perdagangan dan jasa pada Kawasan Tanah Abang yang tidak memiliki tempat tinggal di lokasi yang dekat dengan tempat kerja, yang selain dapat menghemat waktu dan biaya transportasi setiap harinya dan juga untuk meningkatkan sistem permukiman yang terjangkau, sehat, layak huni, serta efisien sehingga dapat mendukung rencana jangka panjang dari Kawasan Tanah Abang sebagai sentra bisnis dan berpotensi menjadi tempat wisata.

\section{KAJIAN LITERATUR}

\section{Tinjauan Isu Permasalahan}

Urbanisasi merupakan fenomena yang tidak dapat dihindarkan. Ketika berurbanisasi manusia juga selalu beradaptasi dan berorientasi. Ketika proses berhuni berevolusi (Paul Oliver,2003) dari berhuni nomaden (shelter of nomads) ke berhuni menetap (settling down) manusia membentuk berhuni, beradaptasi dengan iklim dan mulai memahami ruang. 
Keith Hart (1971) mengatakan bahwa sektor informal banyak digeluti oleh para migran seperti di bidang perdagangan dan jasa yaitu kuli angkut, buruh harian, pedagang kaki lima (PKL), ojek, sebagainya. Bekerja pada sektor informal bagi para migran adalah pilihan paling rasional dalam era persaingan yang sangat ketat. Sebagian penghuni kota berprinsip bahwa kota merupakan tempat untuk mencari penghasilan yang sebesar-besarnya. Dengan demikian prinsip mereka harus hemat dalam arti yang luas, yaitu hemat mendapatkan lahan, pembiayaan pembangunan, pengoperasian dan pemeliharaan, termasuk dalam mendapatkan bahan dan sistem strukturnya (Sobirin, 2001). Dengan prinsip itu, hal yang terjadi justru kawasan perkotaan mengalami degradasi lingkungan yang berpotensi menciptakan kawasan permukiman kumuh (Kompasiana.com, 2016).

\section{Berhuni (Dwelling)}

Kata dwelling dalam Bahasa Inggris kunonya adalah "dwellan" yang berarti mengembara (to wander) dan bertahan hidup (to linger). Dikutip dari kuliah tamu oleh Veronica Gandha (2020) mengenai "Dwelling + Time", secara filosofis kata dwelling memberikan makna bahwa, untuk bertahan hidup, tidak dapat dilakukan dengan berdiam diri atau menetap, tetapi harus mengembara. Dengan menetap dan berkelana inilah manusia belajar tentang konsep menghuni (sebagai ada) di dunia.

Menurut Christian Norberg-Schulz dalam bukunya "The Concept of Dwelling" (1985), "dwelling" atau "berhuni" mempunyai makna lebih mendalam dari sekadar atap yang menaungi di atas kepala kita dan sejumlah meter persegi ruang yang kita miliki. Menurutnya dwelling mempunyai 3 arti; pertama, ruang di mana kita bertemu dengan orang lain untuk bertukar produk, ide, dan perasaan, pada makna ini kita akan mendapatkan pengalaman kehidupan sebanyak mungkin. Kedua, "dwelling" mencapai kesepakatan dengan orang lain di mana kita akan dihadapkan untuk dapat menerima seperangkat nilainilai umum di masyarakat. Ketiga, mengandung arti ketika kita telah menjadi diri kita dengan memiliki dunia kecil pilihan kita sendiri. Kita dapat menyebut ketiga arti itu masing-masing sebagai "dwelling"/ "berhuni" secara kolektif, public, dan pribadi.

\section{Arsitektur Setelah Pandemi Covid-19}

Arsitektur tidak pernah terlepas dari kondisi yang terjadi di luar. "Arsitektur tidak pernah berdiri sendiri, tetapi dia dipengaruhi oleh faktor-faktor eksternal sehingga tidak heran jika pandemi ini sangat berpengaruh pada arsitektur". Dengan adanya pandemi ini memberikan pemahaman lain bahwa persoalan arsitektur adalah persoalan interaksi antara manusia dengan spatial setting-nya (Himasari,2020). Secara refleksi historis perkembangan arsitektur sebagai respons terhadap pandemic, adanya berbagai wabah yang telah melanda dunia, membuat kesadaran masyarakat akan kebersihan dan kesehatan sebagai dasar perancangan kota dan arsitektur semakin besar (Wisiastuti,2020).

\section{Health House}

Menurut Richard Neutra (1929), elemen utama dari mendesain rumah yang sehat adalah banyaknya sinar matahari dan udara segar yang masuk kedalam bangunan. Maka desain jendela/ ventilasi merupakan suatu hal yang harus diperhatikan. Jendela adalah 'mesin', dalam arti bahwa mereka menggabungkan beberapa properti: mereka harus dianggap tidak hanya sebagai bagian transparan dari dinding, tetapi sebagai elemen multi-fungsi penting dari rumah. Desain jendela yang baik dapat meningkatkan kesejahteraan penghuni, baik secara fisik maupun psikologis. Namun, ada sejumlah kendala umum yang justru sebaliknya. Desain kaca yang tidak sesuai dapat memengaruhi privasi, tata letak furnitur, jumlah perolehan sinar matahari, dan kehilangan panas.

\section{Affordable House}


Departemen Perumahan dan Pembangunan Perkotaan (HUD) federal mendefinisikan "tempat tinggal yang terjangkau" sebagai tempat tinggal yang dapat diperoleh dengan kurang dari 30 persen pendapatan rumah tangga. Tetapi ini bervariasi dari kota ke kota. Ada beberapa hal yang perlu diperhatikan dalam membangun hunian terjangkau, seperti pemilihan struktur dan bahan material bangunan, konsep sistem hunian, dan fasilitas yang akan disediakan.

Salah satu konsep sistem hunian yang terjangkau adalah dengan menggunakan konsep sharing. Dalam konsep sharing house, pentingnya menemukan cara untuk membangun penyesuaian diri di antara para penghuni, yang akan berbagi fasilitas dapur, kamar mandi, dan tempat tinggal bersama. Dibutuhkannya kedekatan dengan penghuni lain yang bisa menjadi sulit dinavigasi, khususnya jika penghuni lain berbeda rutinitas sehari-hari, pendekatan untuk kebersihan, atau toleransi terhadap kebisingan (CHPC New York City, June 2019). Cara dasar yang dapat digunakan dalam perumahan bersama adalah untuk menempatkan penghuni yang mempunyai kesamaan bersama. Dengan mengetahui gaya hidup dan rutinitas penghuni yang cocok untuk berbagi ruang komunal (CHPC New York City, June 2019).

\section{METODE}

\section{Metode Riset}

Metode yang digunakan dalam melakukan riset, yaitu dengan studi pustaka dari sumber literatur, jurnal, dan internet. Dalam melakukan investigasi kawasan, dilakukan dengan menggunakan peta dari website googlemaps.com sebagai orientasi awal, dan dicocokan dengan website jakartasatu.jakarta.go.id untuk melihat peta penggunaan lahan. Kemudian untuk memahami aktivitas keseharian dan kondisi sosial ekonomi masyarakat di sekitar kawasan, dilakukan melalui kajian dan analisis terhadap sumber sekunder (media massa, tulisan dalam jurnal, dan sebagainya).

\section{Metode Perancangan}

Dalam kajian terkait dengan proses berhuni para pekerja migran di Kawasan Pasar Tanah Abang, dipilih metode dunia perilaku (behaviour) agar lebih berfokus pada aktivitas penghuninya. Metode dalam dunia perilaku yaitu sebuah wilayah teori yang berpijak pada nilai-nilai perilaku (behavior) manusia dan komunitas (Peta Metode Design, Agustinus Sutanto,2020).

\section{Metode Arsitektur Keseharian}

Studi ini menggunakan pendekatan arsitektur keseharian, yaitu sebuah respon sederhana yang langsung terhubung dengan kenyataan. Arsitektur keseharian tidak membangun melalui ide-ide abstrak, melainkan melihat kenyataan sebagai bahan referensi bertindak.

Dikutip dari e-book Agustinus Sutanto (2020) mengenai "Peta Metode Design", ada tiga proposisi yang dapat ditarik dari pemikiran arsitektur keseharian sebagai berikut:

a. Dengan membaca ruang sosial yang terbentuk dalam masyarakat, semakin mengertilah kita tentang kondisi-kondisi keseharian yang terbentuk.

b. Arsitektur keseharian membuat sesuatu menjadi sangat terbuka (inklusif), dan keterbukaan ini menggiring manusia untuk berpartisipasi dalam berarsitektur.

c. Manusia menciptakan ruang dan ruang turut pula membentuk manusia - manusia menciptakan keseharian dan keseharian turut pula membentuk manusia.

Melalui tiga proposisi ini, maka terdapat tiga taktik dan strategi yaitu: 


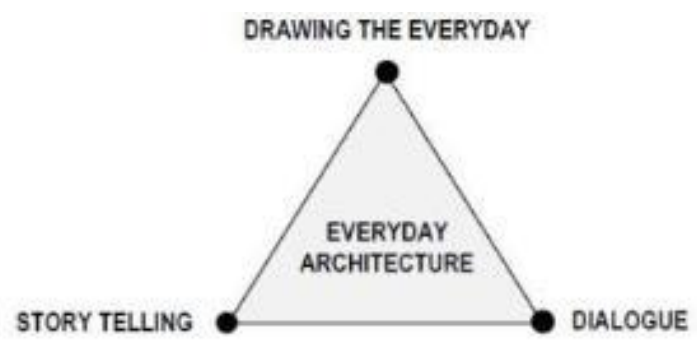

Gambar 2. Diagram Taktik dan Strategi Dalam Membaca Keseharian

Sumber : Peta Metode Desain, Agustinus Sutanto ,2020

\section{Menggambarkan Keseharian (drawing the everyday)}

Untuk menciptakan ruang keseharian kita harus membaca tentang bagaimana masyarakat menghasilkan ruang sosial melalui kesehariannya. Dikutip dari e-book Agustinus Sutanto (2020) mengenai "Peta Metode Design", sebuah pernyataan dari Henri Lefebvre yang paling banyak digunakan dalam memandang hubungan ruang dengan keseharian adalah 'social space is a social product' (Lefebvre, $\mathrm{H}$., The Production of Space, 1991, hal.26). Melalui pernyataan ini, Lefebvre ingin mengatakan bahwa ruang sosial yang ada di masyarakat adalah sebuah produk dari masyarakatnya. Maka dari itu, untuk membaca sebuah kondisi masyarakat kita harus dapat membaca produk sosialnya.

\section{DISKUSI DAN HASIL}

\section{Analisis Lokasi}

Dalam memilih tapak untuk lokasi hunian terdapat beberapa pertimbangan yaitu:

- Terdapat pada Kawasan perdagangan dan jasa yang banyak dikunjungi orang, baik sebagai pembeli maupun pekerja/ pedagang, dan juga menjadi salah satu tujuan para migran untuk mencari pekerjaan di sektor informal.

- Aksesibilitas transportasi umum dan walkable distance.

- Regulasi landuse kawasan, yaitu zona orange dengan fungsi campuran.

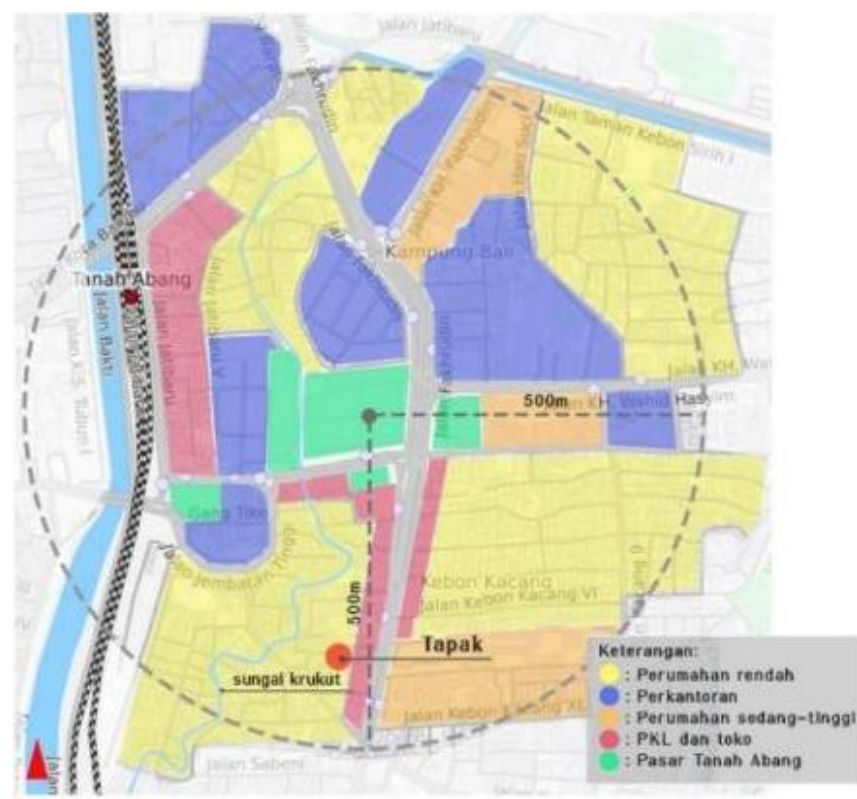

Gambar 3. Peta Zoning Fungsi Lahan di Lapangan Sumber : Googlemaps.com,2020 
Mengacu pada analisis lokasi, maka tapak yang dipilih dalam studi ini akan berada dalam radius 500m dari Pasar Tanah Abang sebagai salah satu pusat perdagangan terbesar di Jakarta, agar penghuni dapat dekat dengan Kawasan tempat mereka bekerja sebagaimana dapat dilihat pada gambar 3.

\section{Data Tapak}
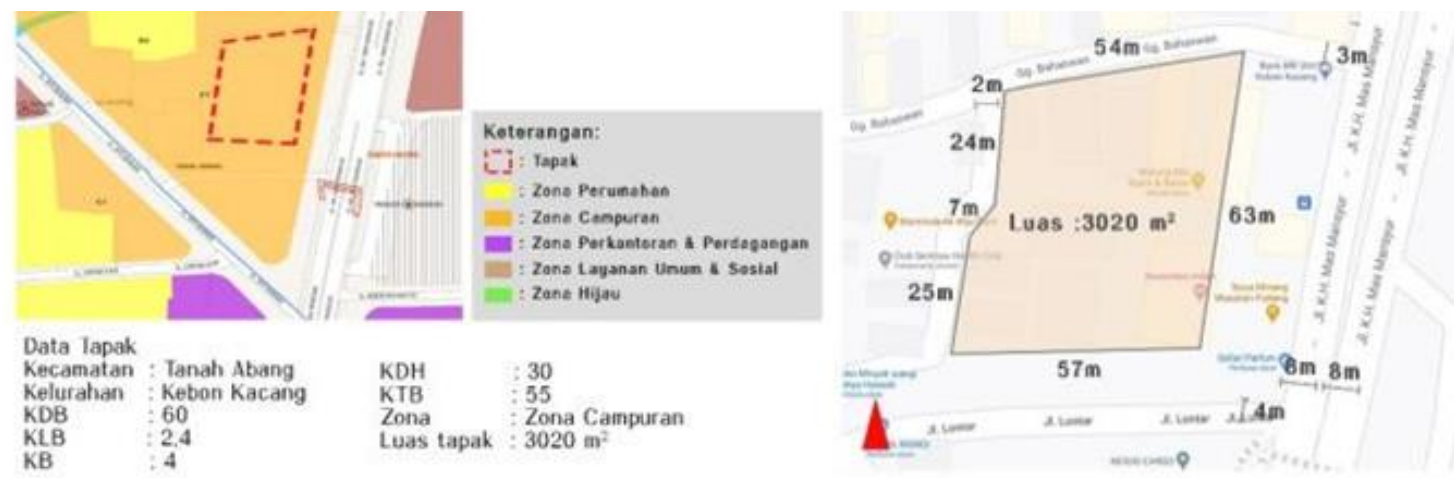

Gambar 4 dan 5. Peta Peruntukan dan Bentuk Tapak

Sumber : Jakartasatu.com, googlemaps.com,2020

Tapak berada pada kecamatan Tanah Abang, Kebon Kacang memiliki peraturan zonasi sebagai berikut :

- Luas site : $3020 \mathrm{~m}^{2}$

- $\quad$ KDB $\quad: 50=1.510 \mathrm{~m}^{2}$

- $\quad \mathrm{KLB} \quad: 2,4=7.248 \mathrm{~m}^{2}$

$-\mathrm{KB} \quad: 4$

- $\mathrm{KDH} \quad: 30=906 \mathrm{~m}^{2}$

- $\quad$ KTB $\quad: 55=1.661 \mathrm{~m}^{2}$

- Jenis Kawasan : Zona Campuran

Tapak yang terpilih berada pada Gang Bahaswan dengan ukuran dan bentuk tapak seperti pada gambar 5.

\section{Analisis Tapak}

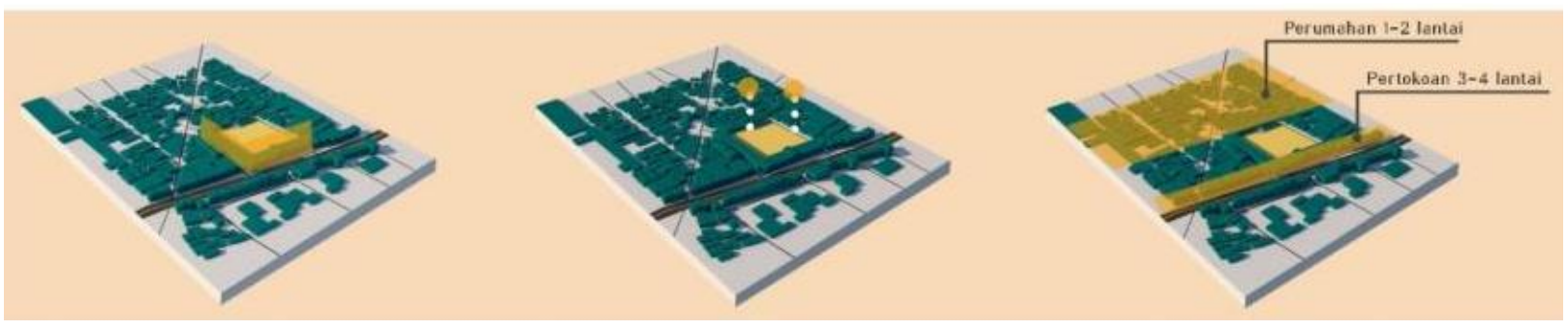

Gambar 6. Proses Analisis Tapak

Sumber: Penulis, 2020

Situasi Tapak dan Lingkungan Sekitar sebagaimana tercantum pada gambar 6 dan 7 menunjukkan bahwa letak tapak berada di belakang pertokoan 3-4 lantai, terdapat 2 entrance menuju tapak dengan lebar jalan $2 \mathrm{~m}$ dan 3m, dan tapak terletak diantara pertokoan 3-4 lantai dan perumahan 2 lantai. 

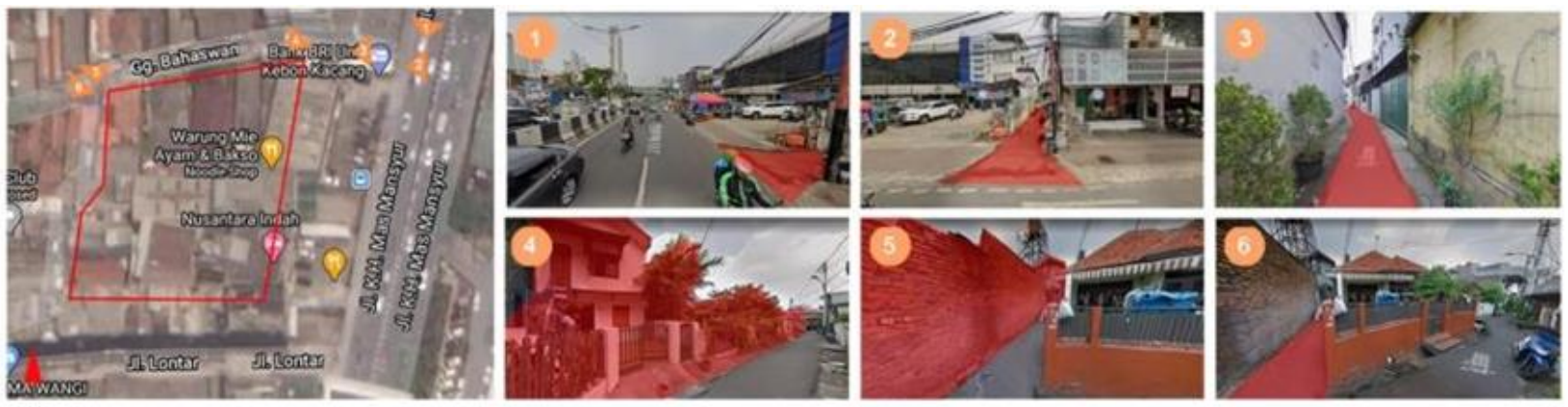

Gambar 7. Tapak dan Lingkungan Sekitar

Sumber : Googlemaps.com,2020

\section{Analisis Program Kegiatan}

Penyusunan program kegiatan dalam rancangan hunian bersama, didasarkan pada kemampuan dalam membingkai kejadian keseharian para target penghuni, sebagai awal untuk membentangkan ruang dan program baru yang dirasakan tepat bagi masyarakat pada sebuah tempat (Peta Metode Desain, Agustinus Sutanto, 2020). Dengan menentukan target penghuni, dan kemudian memetakan aktivitas keseharian mereka, maka kita dapat mengetahui program/ fungsi ruang yang dibutuhkan untuk menunjang aktivitas berhuni dan dapat mewujudkan konsep yang sehat dan terjangkau pada hunian mereka.

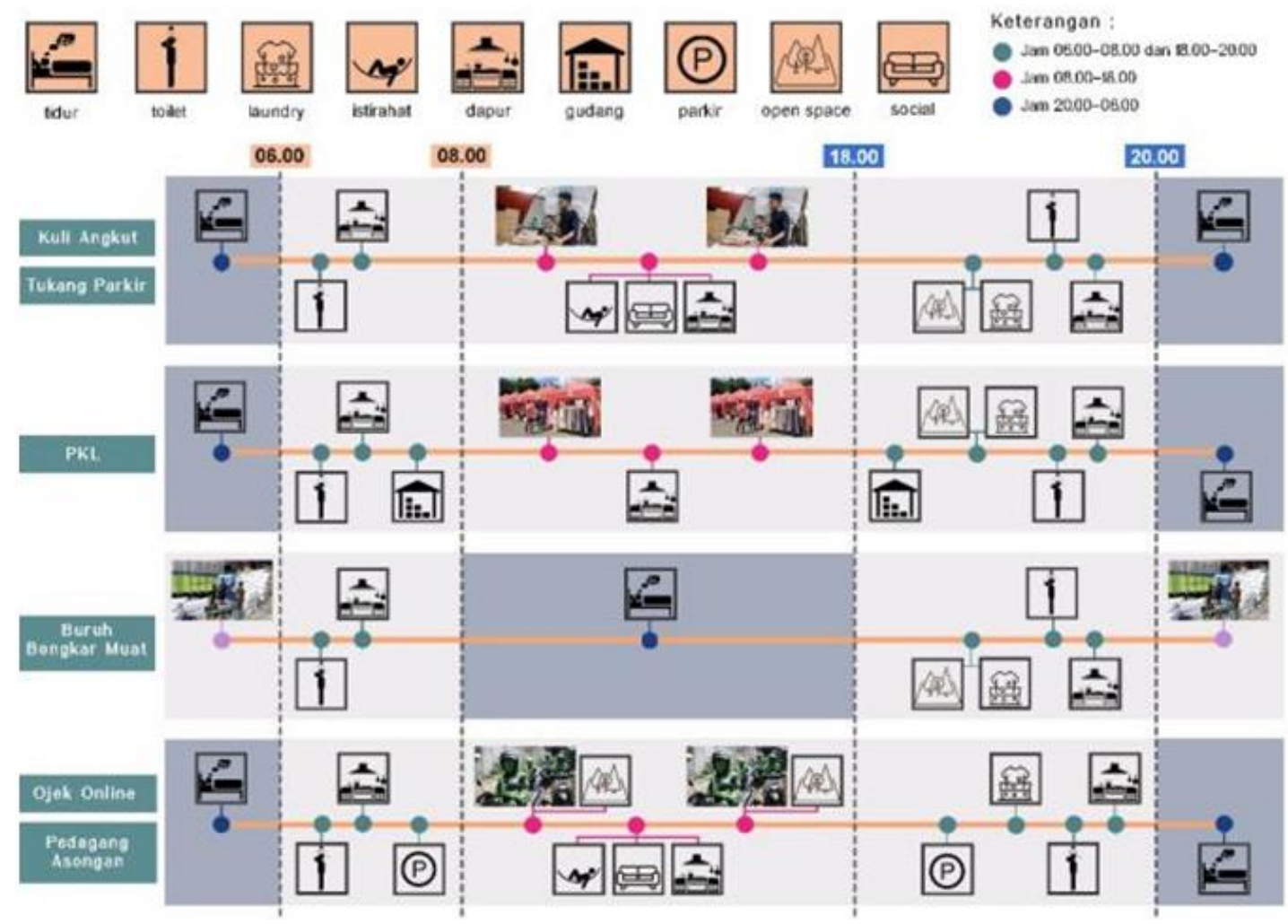

Gambar 8. Diagram Studi Perilaku dan Keseharian Kegiatan Penghuni Sumber: Penulis, 2020 
Melalui analisis perilaku dan keseharian para migran (lihat diagram pada gambar 8) dapat disimpulkan bahwa para pekerja migran di Kawasan Tanah Abang, memiliki waktu kegiatan yang berbeda-beda, sesuai dengan jenis pekerjaan mereka. Sehingga sistem sharing waktu sewa dapat diterapkan pada perancangan bangunan ini misalnya para migran yang bekerja pada malam hari dapat bergantian tidur dengan migran yang bekerja pada siang hari agar dapat mengurangi biaya tempat tinggal mereka.

\section{Konsep Gubahan Massa}

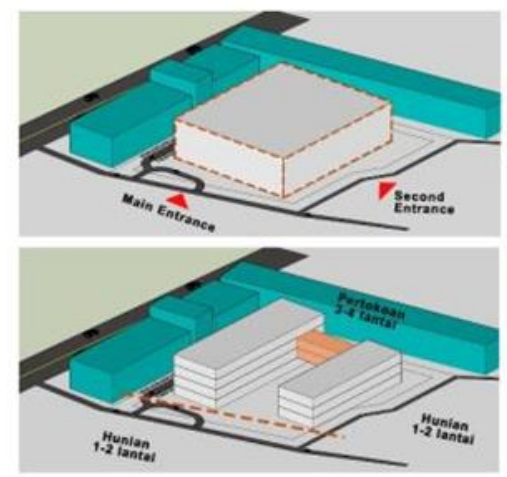

Gambar 9. Konsep Gubahan Massa

Sumber: Penulis, 2020

Gubahan massa bangunan didasarkan pada zoning area pada bangunan. Berikut proses gubahan massa yang terbagi menjadi lima tahapan :

a. Massa dasar bangunan berbentuk persegi yang mengikuti tapak. Dengan diapit 2 jalan sebagai main dan second entrance.

b. Massa dibagi menjadi 2 bagian, menurut zoning private dan public. Sehingga pada tengah bangunan terdapat lorong yang dapat memiliki fungsi yang serupa dengan gang perumahan pada kampung.

c. Massa kedua dimundurkan mengikuti garis tapak, dan dibuat 3 lantai agar dapat menyeimbangkan dengan tinggi perumahan disekitarnya.

d. Pada bagian depan, massa dibuat berundak sehingga dapat menjadi ruang outdoor bagi penghuni.

e. Tampak massa bangunan dibentuk dari komposisi 3 bagian/material yaitu void, transparent, dan solid. Sehingga cahaya matahari dan sirkulasi udara dapat memasuki bangunan.

\section{Analisis dan Konsep Program Ruang}

Program ruang dibagi menjadi tiga zoning yaitu, zoning private (kamar tidur bersama), zoning semi private (kamar mandi bersama, dapur bersama, laundry, area bersama, ruang penyimpanan, dan area parkir motor), dan zoning public (area multifungsi, play area, dan perpustakaan). Hal ini dapat dilihat pada gambar 10 tentang Program Kegiatan pada Bangunan. 

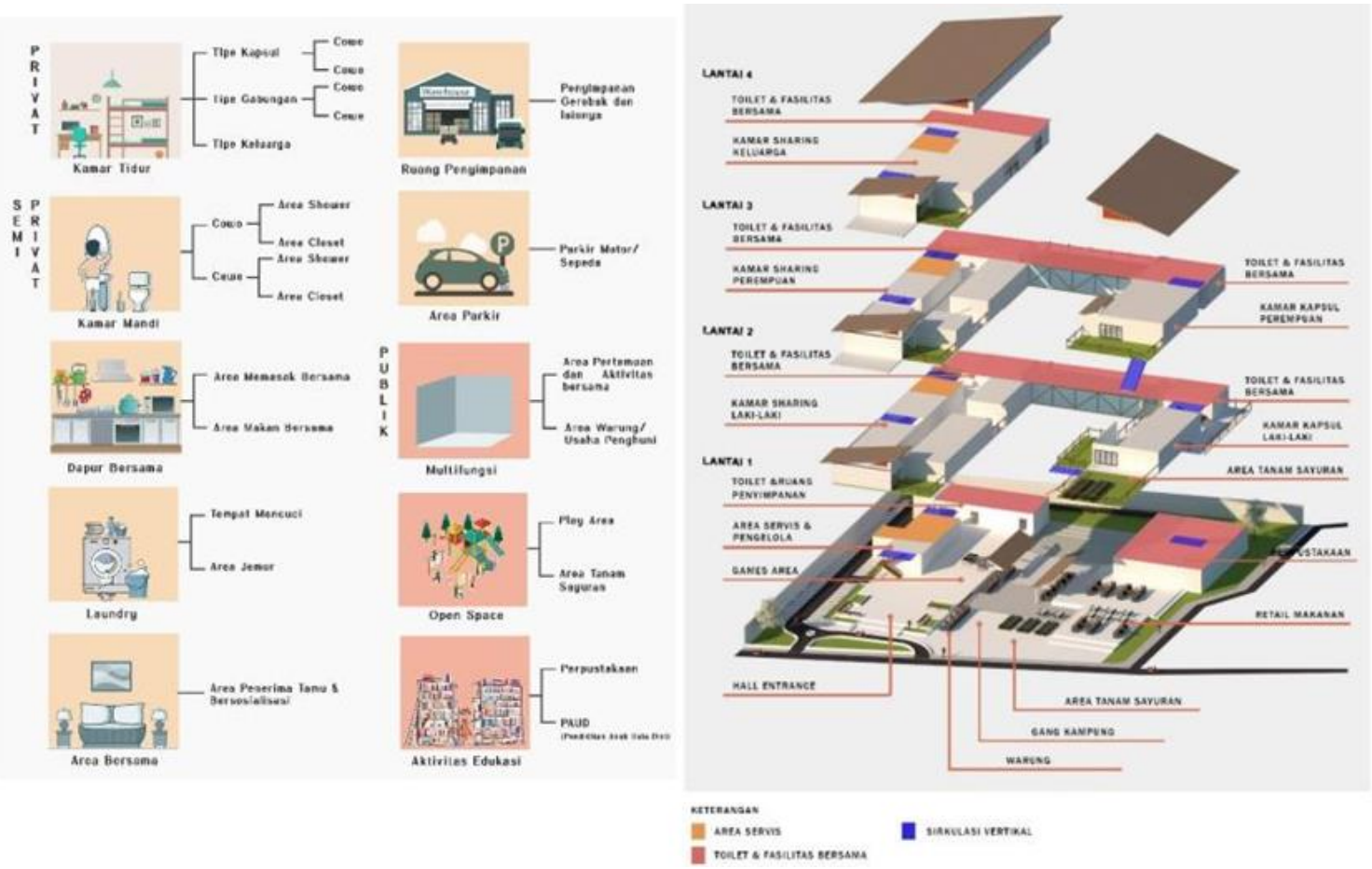

Gambar 10 dan 11. Program dan Zoning Kegiatan pada Bangunan

Sumber: Penulis, 2020

Zoning bangunan menunjukkan hubungan dan peletakan ruang baik vertikal maupun horizontal yang mempengaruhi pergerakkan pengguna. Bangunan terdiri dari dua massa, pada massa pertama memiliki 4 lantai dan zoning yang lebih private seperti entrance penghuni, ruang penyimpanan bagi barang pekerja migran, kamar sharing laki-laki, perempuan, dan keluarga. Sedangkan pada masa kedua yang mempunyai 3 lantai digunakan untuk perpustakaan, retail makanan, area tanam sayuran, dan kamar kapsul. Hal ini dapat dilihat pada gambar 11 tentang program dan zoning kegiatan pada bangunan.

\section{Konsep Perancangan}

Konsep Hunian Sehat

Dilakukan penyusunan komposisi antara area terbuka dan hunian/ unit agar bangunan mempunyai sirkulasi udara yang baik dan sehat, juga terdapat kisi-kisi tanaman pada setiap balkon hunian agar bangunan terlihat asri dan segar.

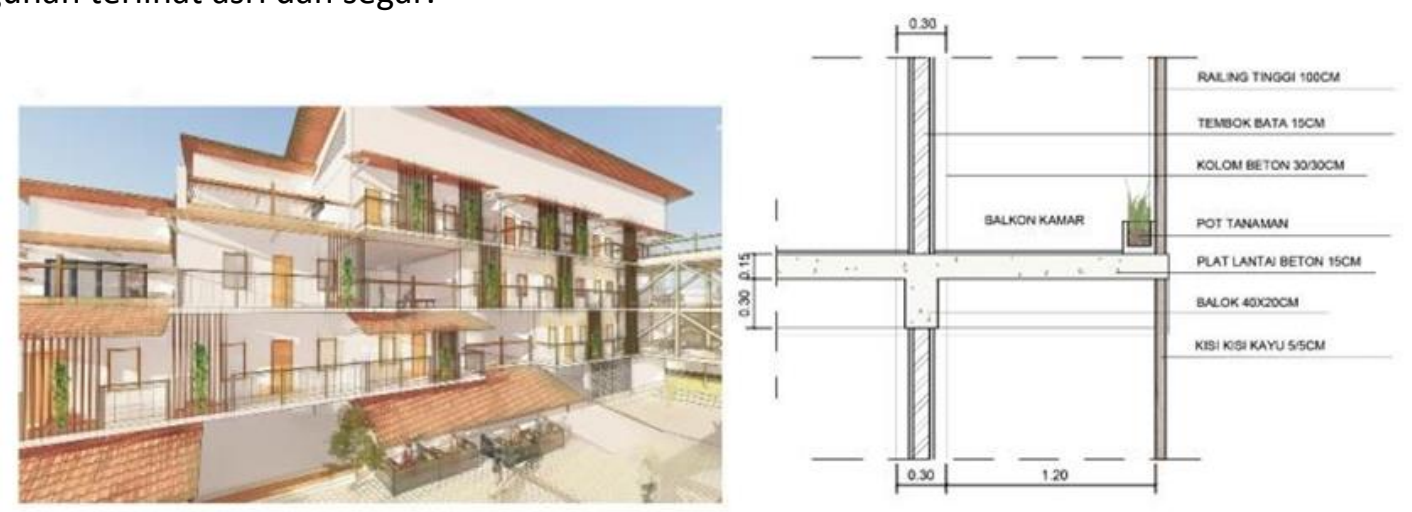

Gambar 12 dan 13. Tampak dan Detail Fasad Hunian Sumber: Penulis, 2020 
Pada setiap balkon hunian/ kamar terdapat kisi-kisi yang berfungsi sebagai estetika, dengan material kayu $5 \times 5 \mathrm{~cm}$, juga dapat menjadi tempat tanaman untuk menjalar. Pada setiap lantai hunian memiliki beberapa ruang outdoor/ area bersama yang dapat dimanfaatkan oleh penghuni.

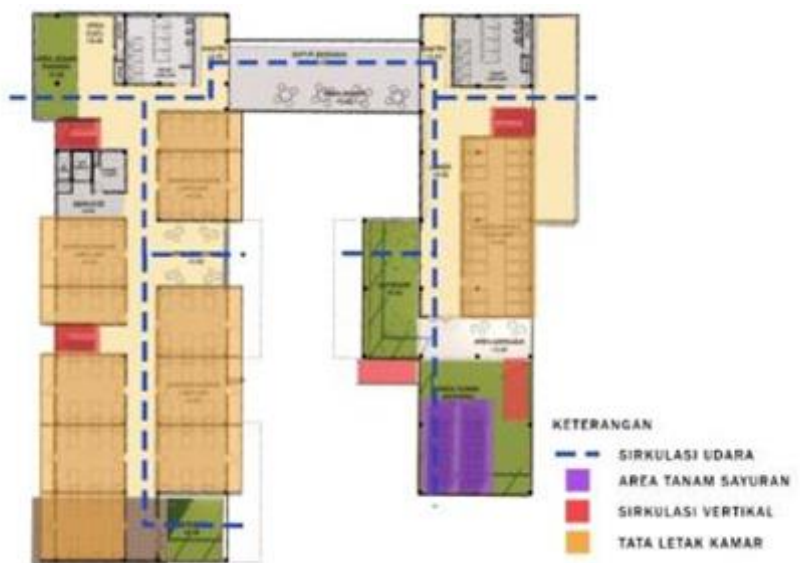

Gambar 14. Penerapan Konsep Health Pada Bangunan

Sumber: Penulis, 2020

\section{Konsep Keterjangkauan (Affordable)}

Sistem hunian, material/ struktur, dan fasilitas yang ada dalam hunian perlu disesuaikan dengan ratarata pendapatan mereka. Terdapat tiga kemungkinan jumlah anggota penghuni yang akan menempati hunian ini, yaitu keluarga kecil, bujangan, dan suami-istri, maka program hunian akan menyediakan tiga tipe kamar :

- Tipe Kapsul bagi target migran bujangan yang ingin tidur sendirian dan dalam waktu singkat.

- Tipe sharing bagi target migran bujangan yang memilki upah terbatas, sehingga memilih untuk sharing kamar tidur.

- Tipe Keluarga bagi target migran keluarga yang ingin tinggal sementara di kota.
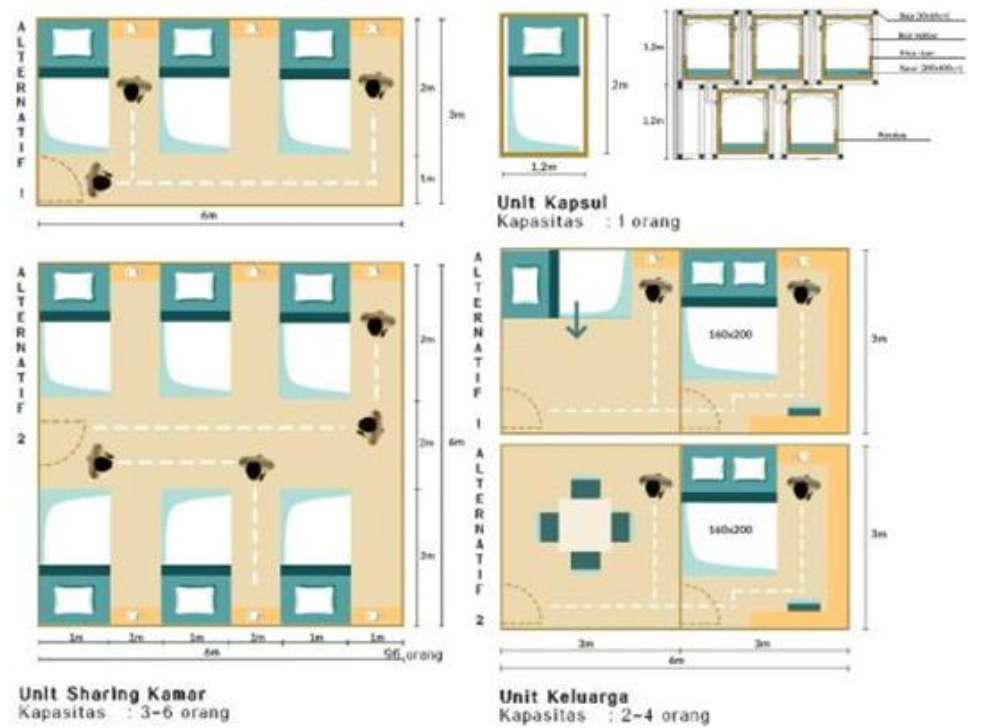

Unit Sharing Kamor
Kapasitas $: 3=6$ orang

Kapasitas:2-4 orang

Gambar 15. Tipe Kamar Pada Hunian

Sumber: Penulis, 2020 


\section{Konsep Arsitektur Ekologis}

Ketika menghuni meskipun sementara, penghuni tetap dimungkinkan untuk menghasilkan sendiri kebutuhannya sehari-hari, seperti adanya area tanam sayuran pada hunian yang dapat dimanfaatkan oleh penghuni. Area tanam ini selain mempunyai nilai ekonomi, juga dapat berfungsi ekologis karena dapat menghasilkan oksigen, dan memberikan suasana menyenangkan bagi migran yang didera kesibukan mencari nafkah.

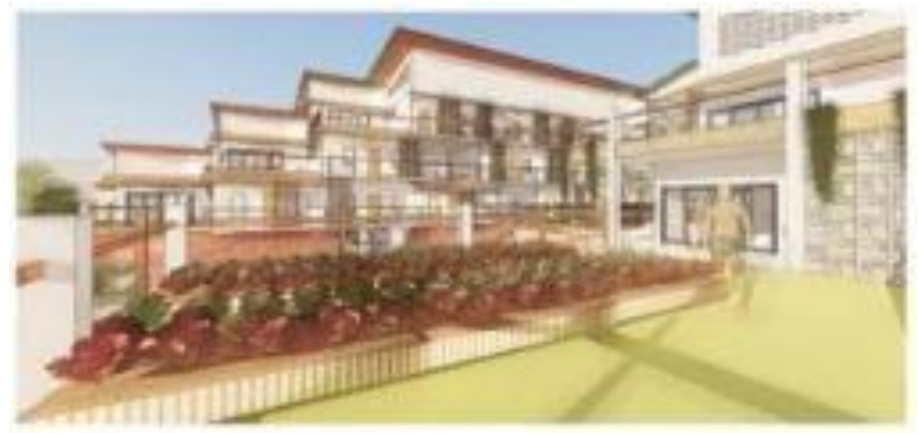

Gambar 16. Penerapan Konsep Arsitektur Ekologis Pada Bangunan Sumber: Penulis, 2020

\section{Konsep Siteplan dan Aksesibilitas Bangunan}

Tapak menghadap kearah Gg. Bahaswan yang mempunyai lebar $3 \mathrm{~m}$ (lihat gambar 4). Lebar jalan ini membuat gang hanya dapat dilalui oleh motor, karena jalan yang sempit dan membelok. Lebar jalan ini menjadi pertimbangan entrance depan/utama kendaraan dari bangunan. Terdapat beberapa entrance pejalan kaki baik pada setiap sisi bangunan, pada side entrance dari parkir motor, dari perumahan warga sekitar, maupun pada entrance utama dari arah jalan didepan tapak.

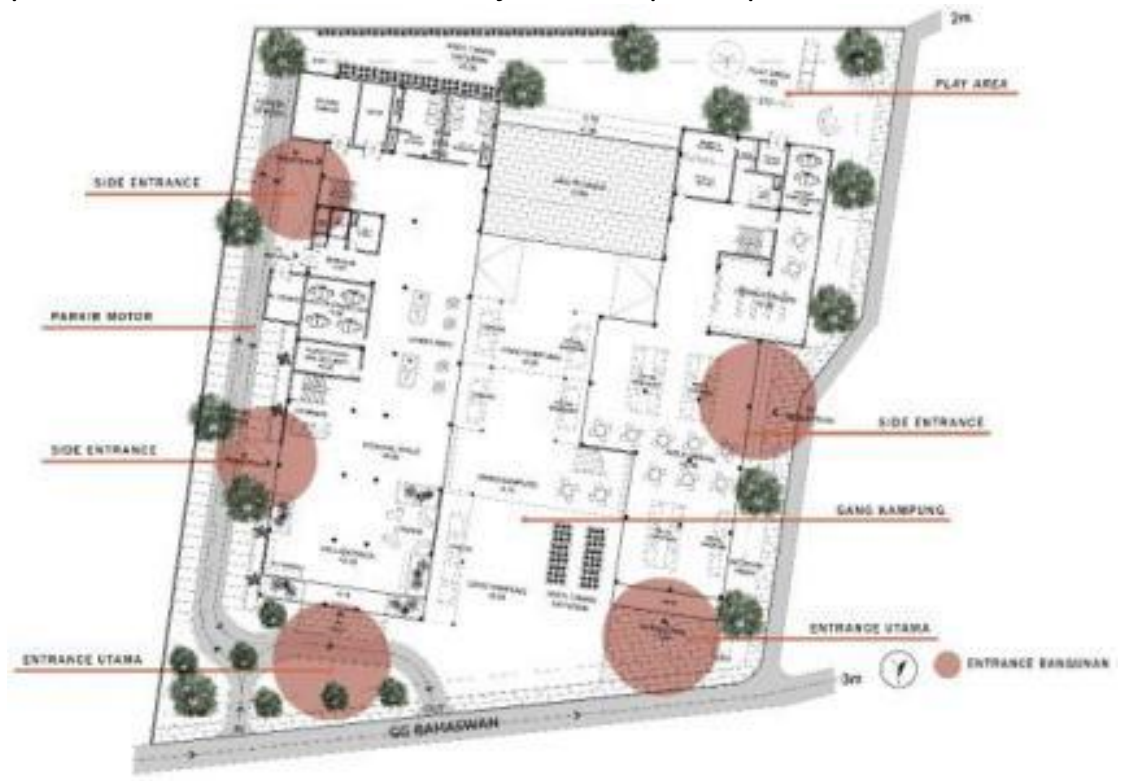

Gambar 17. Siteplan

Sumber: Penulis, 2020 
Sebagai penerapan metode keseharian yang mengadopsi cara bermukim dan bentuk interaksi keseharian di permukiman di kampung kota ke dalam tapak, maka desain area outdoor di antara bangunan dibuat mirip dengan suasana yang sering ditemui pada gang perkampungan di Jakarta. Gang yang dibuat diantara 2 massa bangunan, dimanfaatkan sebagai area bermain, warung, dan tegur sapa antar penghuni serta untuk area tanam sayuran.
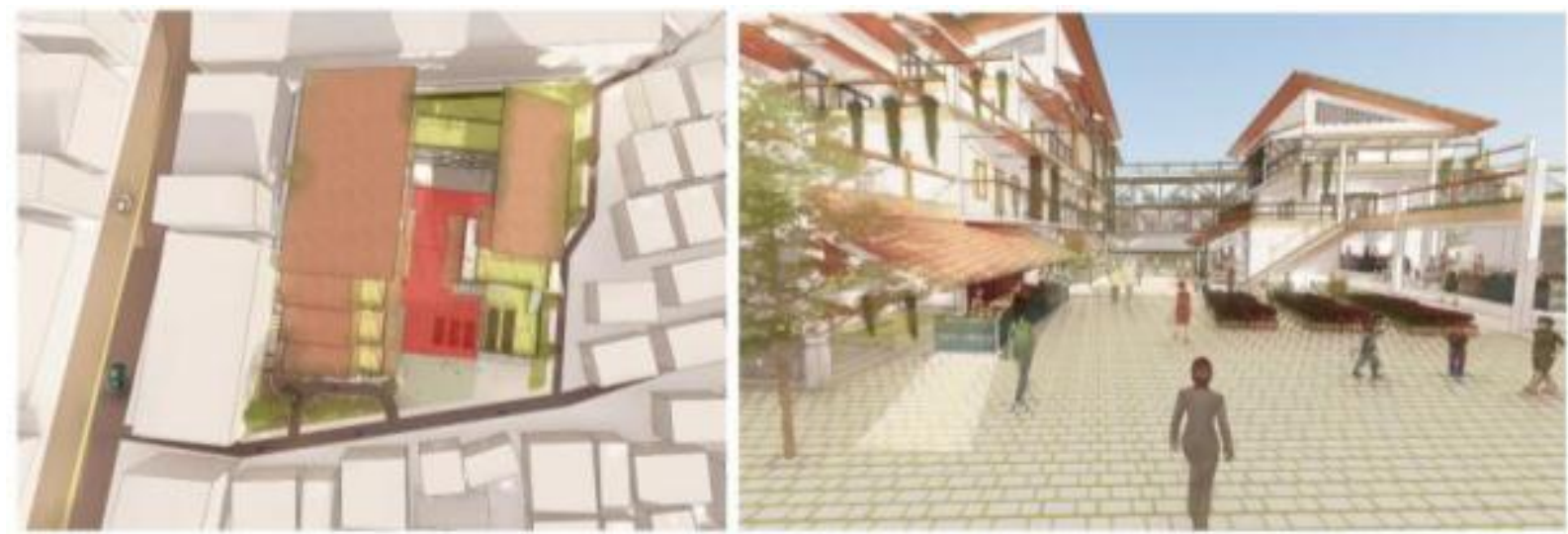

Gambar 18 dan 19. Gang Kampung

Sumber: Penulis, 2020

\section{Konsep Struktur Bangunan}

Struktur bangunan (lihat gambar 19) memakai atap miring dengan konstruksi kayu dan terdapat talang air yang dapat digunakan untuk menampung air hujan. Juga menggunakan struktur balok dan kolom sederhana sehingga biaya pembangunan terjangkau, sedangkan pada jembatan penghubung menggunakan struktur baja. Pada masing-masing massa terdapat 2 tangga (sirkulasi vertikal) yang dapat juga difungsikan sebagai tangga darurat oleh penghuni.

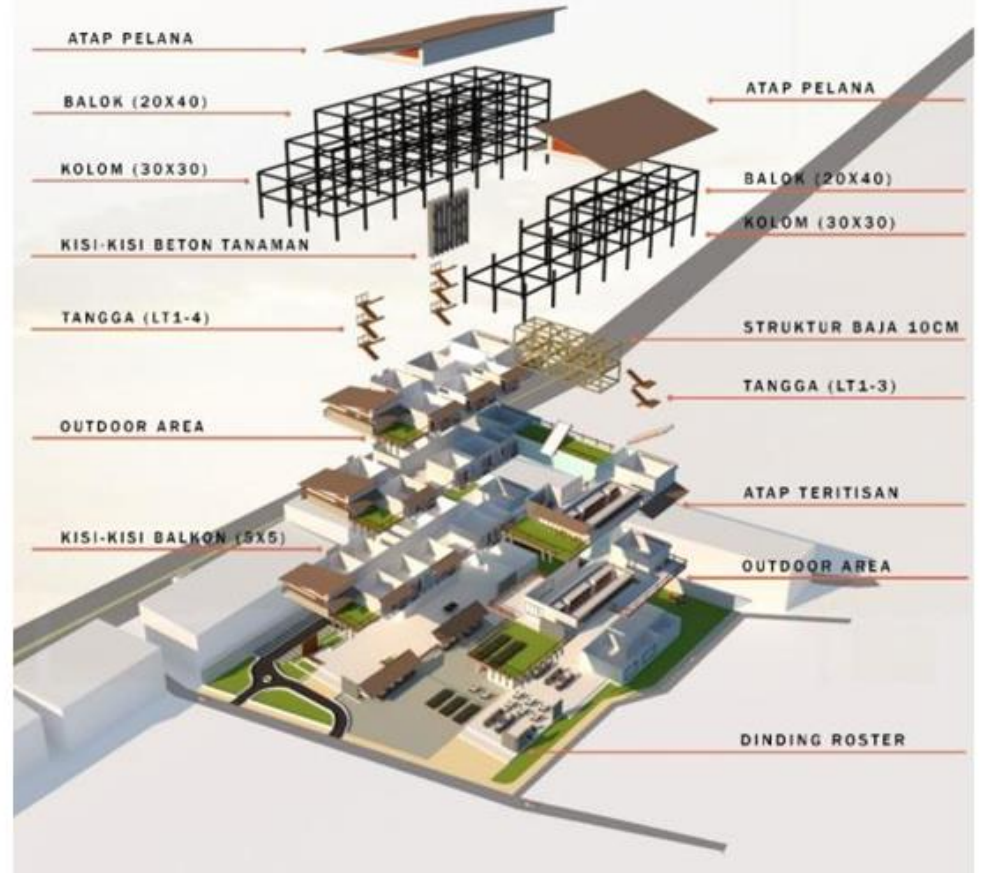

Gambar 20. Axonometri Struktur Bangunan

Sumber: Penulis, 2020 


\section{Desain Ruang Dalam}

Dalam desain ruang dalam bangunan mempunyai karakter accessible, private, conversation, dan open yang menunjukkan aktivitas yang bersifat privasi namun tetap terbuka dan nyaman untuk menjadi tempat tinggal bersama bagi para pekerja migran. Setiap ruang mendapatkan pencahayaan dan pengudaraan alami yang baik.
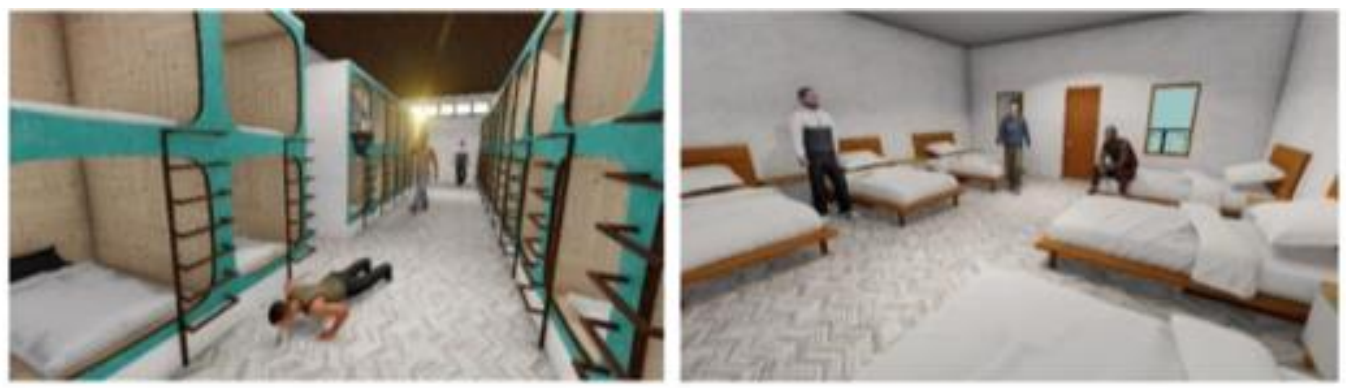

Gambar 21 dan 22. Perspektif Kamar Kapsul dan Sharing Kamar Laki-laki Sumber: Penulis, 2020

\section{KESIMPULAN DAN SARAN}

\section{Kesimpulan}

Studi tentang penerapan konsep health and affordable dalam perancangan hunian di Kawasan Pasar Tanah Abang ini menghasilkan suatu rancangan proyek hunian bersama bagi pekerja migran informal di sekitar kawasan dan diharapkan proyek ini mampu menyediakan hunian yang sehat dan terjangkau dengan mempertimbangkan daya sewa dari target penghuninya, yang disesuaikan dengan material/ struktur, furniture, dan fasilitas yang didapatkan. Pemetaan aktivitas keseharian dari para target penghuni sangat perlu dilakukan agar program/fungsi ruang yang ada dalam hunian dapat dimanfaatkan dengan baik dan dapat menjadi jawaban akan permasalahan dan kebutuhan masyarakat akan hunian yang layak di Kawasan Tanah Abang terutama bagi para migran. Dengan program sharing kamar, kamar kapsul, fasilitas bersama lainnya, serta retail makanan pada bangunan diharapkan dapat membantu meningkatkan kesejahteraan dan dapat menumbuhkan rasa kekeluargaan antar penghuninya yang berasal dari luar kota/ migran.

\section{Saran}

Dalam merancang hunian bersama bagi para pekerja migran kondisi sosial, ekonomi, budaya dan kebiasaan masyarakat setempat menjadi hal yang penting agar hunian dapat menjadi wadah yang dibutuhkan dan menjadi jawaban atas permasalahan yang dihadapi oleh masyarakat.

\section{REFERENSI}

Badan Perencanaan Pembangunan Nasional. (2019). Peran Sektor Informal Sebagai Katup Pengaman Masalah Ketenagakerjaan. Diakses di https://www.bappenas.go.id.

Charara, S. (2018). What the smart home will look like in 2020, 2040 and beyond. Diakses di https://www.the-ambient.com /features/future-of-smart-home-timeline-310.

Dinas Kependudukan dan Pencatatan Sipil Provinsi DKI Jakarta. (2016). Migrasi Penduduk Di Provinsi DKI Jakarta, 2015. 
Heidegger, M. (1962). Being and Time. translated by John Macquarrie \& Edward Robinson. Oxford: Blackwell Publishers Ltd.

Heidegger, M. (1971). Dwelling Thinking Building, from Poetry, Language, Thought, translated by Albert Hofstadter, Harper Colophon Books, New York.

Jayani, D. H. (2019). Proyeksi Jumlah Penduduk DKI Jakarta 2020. Diunduh 25 desember 2020, diakses di https://databoks.katadata.co.id/datapublish/2019/12/07/jumlah-penduduk-dki-jakarta-2020.

Norberg-Schulz, C. (1985). The Concept of Dwelling: on the way to figurative architecture. New York : Rizzoli

Permana, A. (2020). Bagaimana Kondisi Arsitektur Setelah Pandemi. Diakses di https://www.itb.ac.id/news/read/57599/home /bagaimana-kondisi-arsitektur-setelah-pandemi.

Sutanto, A. (2020). Peta Metode Design, Jakarta: Universitas Tarumanagara. 